\title{
Foraging association of lionfish and moray eels in a Red Sea seagrass meadow
}
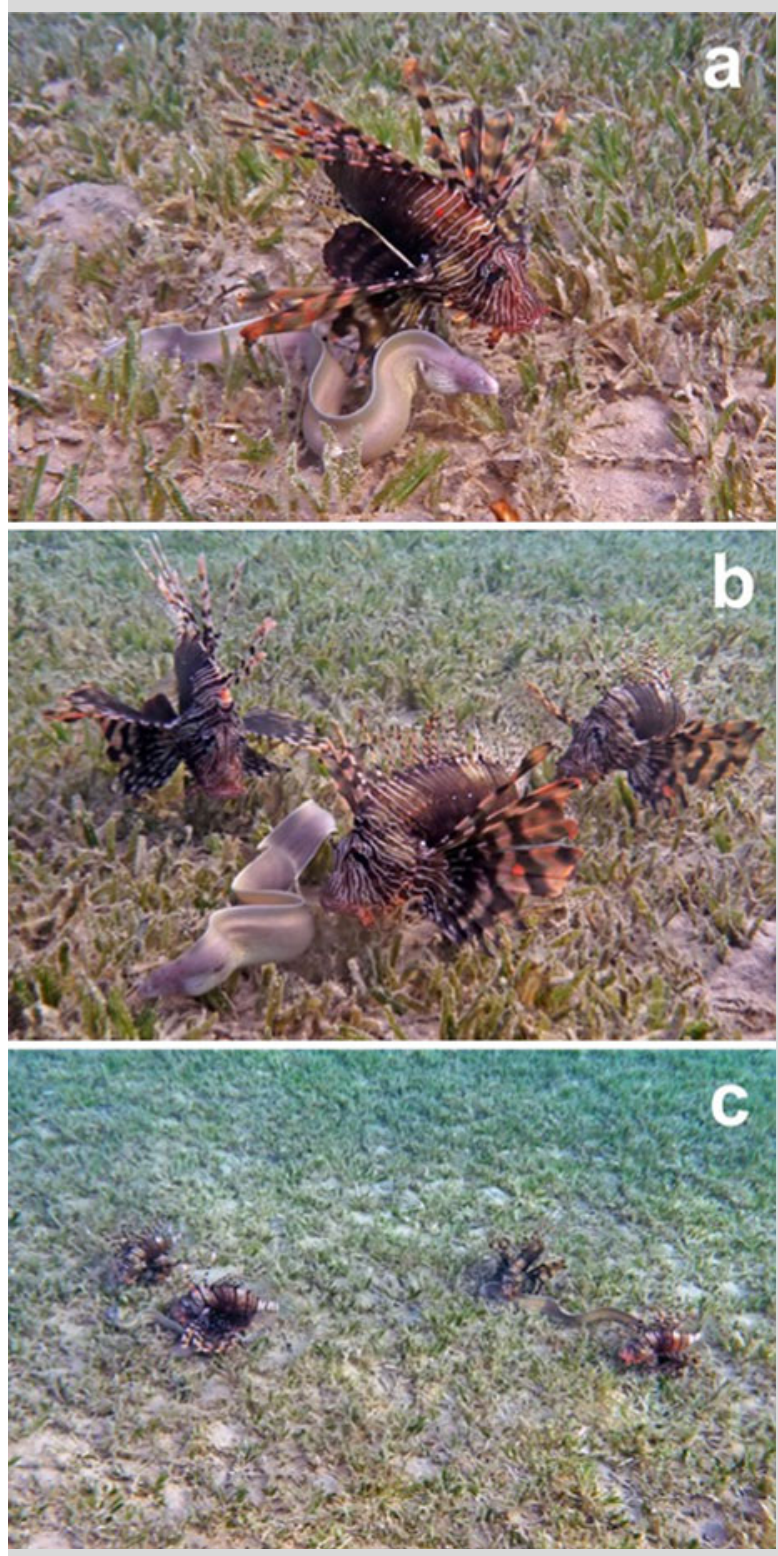

Fig. 1 Interspecific foraging association of the lionfish Pterois volitans with the moray eel Gymnothorax griseus in a Red Sea seagrass meadow. a Attendant association by an individual lionfish displaying its hunting posture (i.e., lowered head, flared pectoral fins) and a moray eel, $\mathbf{b}$ a group of three lionfish associated with a foraging moray eel, panel $\mathbf{c}$ two groups of lionfish-moray eel associations: In each group, two lionfish attend one moray eel
Interspecific foraging associations of fish occur as shoaling or attendant interactions and can generate important benefits such as increased prey availability and reduced predation risk for the involved fishes (Lukoschek and McCormick 2002). Key elements of an interspecific attendant foraging association are the nuclear species, initiating and maintaining foraging associations, and the associated species that follow the foraging nuclear species for varying periods of time. Further, certain interspecific attendant foraging associations are highly communicative and cooperative (Bshary et al. 2006). Here, we report on the attendant foraging association of the lionfish Pterois volitans with the moray eel Gymnothorax griseus, as observed in a shallow coastal seagrass meadow located in the Gulf of Aqaba, Red Sea, close to Dahab, Egypt. On six consecutive days (1-6 March 2013), individual $P$. volitans or groups of conspecifics $(\leq 3)$ were observed in close association with individual $G$. griseus foraging between seagrass leaves during the afternoon (Fig. 1a, b). Associations were initiated when lionfish spotted moray eels from the water column, subsequently following them and then attending $G$. griseus forays, thereby displaying their species-specific hunting posture (i.e., lowered head, flared pectoral fins) (ESM 1). This close association was maintained for extended periods $(>1 \mathrm{~h})$, during which $G$. griseus hunted or rested, while $P$. volitans either scavenged on startled benthic prey organisms or remained on alert. Such interspecific groups were observed in close vicinity to each other (Fig. 1c) and occasionally merged to larger groups consisting of two $G$. griseus and up to four P. volitans (ESM 1). Based on our observations, we classify this attendant foraging association as the following and scavenging type (Ormond 1980), where G. griseus acts as a nuclear species and P. volitans as an attendant commensal. Potential specific benefits for both associated predators remain to be investigated.

Acknowledgments We would like to thank H.R. Lasker and two anonymous reviewers for their help in improving the manuscript.

\section{References}

Bshary R, Hohner A, Ait-el-Djoudi K, Fricke H (2006) Interspecific communicative and coordinated hunting between groupers and giant moray eels in the Red Sea. PLoS Biol 4:e431

Lukoschek V, McCormick MIA (2002) A review of multi-species foraging association in fishes and their ecological significance. Proc 9th Int Coral Reef Symp: 467-474

Ormond RFG (1980) Aggressive mimicry and other interspecific feeding associations among Red Sea coral reef predators. J Zool Lond 191:247-262

Electronic supplementary material The online version of this article (doi:10.1007/s00338-013-1079-0) contains supplementary material, which is available to authorized users.

M. S. Naumann ( $\square) \cdot$ C. Wild

Coral Reef Ecology Group (CORE), Leibniz Center for Tropical Marine

Ecology (ZMT), Fahrenheitstr. 6, 28359 Bremen, Germany

e-mail:mnaumann@uni-bremen.de

URL: http://www.zmt-bremen.de

C. Wild

Faculty of Biology and Chemistry, University of Bremen,

NW 2/Leobener Str., 28359 Bremen, Germany 